\title{
SENTIDOS DO CORPO: METÁFORA E INTERDISCURSO*
}

\author{
Aline Fernandes de Azevedo* \\ Universidade Estadual de Campinas \\ Campinas, São Paulo, Brasil
}

\begin{abstract}
Resumo: Sustentado na teorização do corpo como forma material, este artigo apresenta a análise de dois recortes selecionados no Facebook e que trazem como marca principal a inscrição na pele do sujeito, pelo traço na carne. Nele, procuro tecer considerações acerca do funcionamento da metáfora e do interdiscurso, privilegiando-os como forma de dar visibilidade aos procedimentos teórico-analíticos e refletir sobre as especificidades da análise de discurso de filiação pêcheutiana em estudos de textualidades verbovisuais. As textualidades analisadas permitem ver as inscrições corporais como marca da contradição $e$ da divisão, sinais de pertencimento capazes de produzir efeitos de sentido de multiplicidade e transparência, em um corpo caleidoscópico e polifônico.
\end{abstract}

Palavras-chave: Análise de discurso. Textualidade verbovisual. Corpo. Inscrição na pele.

\section{INTRODUÇÃO}

Apresento neste artigo a análise de dois textos multimodais a partir do referencial teórico da Análise de Discurso, particularmente da vertente que se desenvolve no Brasil filiada à obra de Michel Pêcheux. Dentre as especificidades desse posicionamento teórico, a articulação da textualidade com o esquecimento e a memória, em relação ao postulado da contradição e da incompletude, configura o ponto nodal do pensamento de Pêcheux (2009) ${ }^{1}$, que sistematiza seus procedimentos de análise com a teorização do interdiscurso como exterioridade constitutiva do discurso, ou seja, o já-dito que torna possível todo dizer.

Conceitos como interdiscurso, efeito de pré-construído, memória, paráfrase, metáfora e formação discursiva (PÊCHEUX, 2009; 2011; 2007) são articulados à textualidade analisada, de modo a possibilitar a compreensão dos processos de produção de sentidos presentes nesses recortes. Embora não pretenda dar conta da teorização de todos os conceitos citados na análise, privilegio a explicitação das noções de metáfora e interdiscurso, que se mostram fundamentais para a compreensão dos procedimentos teórico-analíticos da Análise de Discurso e da análise apresentada. Ao final do texto, o leitor poderá reconhecer esses procedimentos, bem como a produção dos efeitos de préconstruído e sustentação, permitindo ver a complexidade do pensamento de Pêcheux e da análise de discurso franco-brasileira.

\footnotetext{
* Este texto apresenta a análise de dois recortes que figuram na tese Cartografias do corpo: metáforas contemporâneas da sutura e da cicatriz, defendida no Instituto de Estudos da Linguagem da UNICAMP, sob a orientação da Professora Doutora Eni P. Orlandi, em 2013.

** Doutora em Linguística pela Universidade Estadual de Campinas (UNICAMP). Pesquisadora CAPESPNPD do Instituto de Estudos da Linguagem da UNICAMP. Email: azevedo.aline@gmail.com.

${ }^{1}$ A primeira edição de Les vérités de La Palice foi publicada em francês em 1975. Em 1988, a primeira tradução foi publicada no Brasil com o título Semântica e Discurso. Uma crítica à afirmação do óbvio. Utilizo neste trabalho uma edição recente publicada em 2009.
} 
A análise mostra o movimento de constituição de sentidos sobre/do corpo, especialmente da inscrição corporal como produtora de uma polifonia relacionada à quantidade e à multiplicidade, polifonia que se assenta na pretensa transparência da imagem. Nas malhas de sentidos da Web, especialmente numa rede social como o Facebook, as significações sobre/do corpo são decididas em movimentos tensos e contraditórios, embates que, historicamente, vão constituindo sentidos para os corpos através de um profundo processo de transferência. Esse processo é explicitado na análise, que indica duas formas de interpretar as inscrições na pele: a) quando a marca na pele metaforiza um rito primitivo, inscrevendo-se em uma prática discursiva; $b$ ) quando a inscrição corporal significa o grupo-corpo, pelo funcionamento da metonímia.

Consideramos que há um investimento social no modo de produção de objetos simbólicos nas redes virtuais, especialmente da formulação e circulação de um discurso sobre/do corpo como prática atravessada por um processo informático-midiático de produção de sentidos. As imagens do corpo que se produzem e circulam na Web, em sua forma sobredeterminada pela mídia, passam a compor um universo de evidências de sentidos que naturalizam certas significações para os corpos dos sujeitos, a partir das formações ideológicas. É nesse processo que os sentidos de beleza e diferença se constituem, através de um jogo parafrástico de filiações históricas que o determinam, mas que, apesar disso, jamais se estabiliza completamente. A prática da exposição acentuada da vida cotidiana na Web, com destaque para cliques e postagens que congelam cenas de festividade e comemorações, torna ainda mais evidente $\mathrm{o}$ investimento social no corpo do sujeito, permitindo ver o movimento de sentidos atravessado pela ideologia e pelo inconsciente.

\section{CORPO COMO FORMA MATERIAL}

Tendo em vista nosso objeto, interessa-nos compreender o corpo como discurso, considerando o modo como a corporalidade é formulada em diferentes materialidades significantes. Esse posicionamento exige, pois, uma apurada reflexão sobre os diversos instrumentos de análise e os diferentes gestos de interpretação (ORLANDI, 2007). Ele coloca em jogo, ainda, a relação entre a materialidade e a história, permitindo compreender o trabalho simbólico da contradição e da incompletude (PÊCHEUX, 2009).

A materialidade é, nesses termos, o modo significante pelo qual o sentido se formula (LAGAZZI, 2010). Assim, ao analisar o corpo textualizado em diferentes materialidades significantes, procuramos mostrar que a própria corporalidade é também uma materialidade significante, discursividade inscrita em condições de produção fronteiriças.

Se, por um lado, a incompletude (e o movimento que ela instaura) permite o sentido, a errância dos sentidos e dos sujeitos (ORLANDI, 1995), por outro a contradição indica a divisão a que estão sujeitos os objetos ideológicos (PÊCHEUX, 1990). É por isso que a posição materialista exige que se assuma o equívoco e a falha, o silêncio como possibilidade mesma da significação. E isso tem forte relação com a 
materialidade significante, que deve ser tomada em sua opacidade, em sua não transparência. Diferentes materialidades possuem funcionamentos discursivos diferentes, e o analista de discurso deve ser sensível a essas diferenças.

Diante da banalização da noção de materialidade, Orlandi (2012, p. 42) preocupase em indicar a filiação materialista tecendo críticas sobre o equívoco teórico que não distingue o "objeto teórico (o discurso: efeito de sentido entre locutores) e objetos de análise (que são muitos e de muitas naturezas)". Segundo a autora, a materialidade é que permite vislumbrar a ideologia funcionando pelo inconsciente, na relação do real com o imaginário.

A partir dos dizeres de Pêcheux (2009), Orlandi afirma que a forma discursiva é material, portanto, não é empírica, nem abstrata, mas parte do processo histórico-social que engloba o sujeito e o sentido, promovendo uma redefinição do político como divisão: "divisão entre sujeitos e divisão do sujeito - já que nossa formação social é dividida e a interpelação do indivíduo em sujeito produz uma forma histórica que é a capitalista de que resulta um sujeito dividido, ao mesmo tempo determinado e determinador" (ORLANDI, 2012, p. 72-73).

Tomar as diferentes linguagens como formas materiais é dizer que não há apenas um sistema de signos, porque os modos de significar e a matéria significante são plurais: o corpo é um lugar de opacidade que ganha sentido pelo olhar. Pela filiação teórica ao materialismo histórico, a forma material é sempre histórica. Em outras palavras, tomar o corpo como forma material implica afastar qualquer concepção que o trate como realidade empiricamente compreensível e biologicamente funcional, comuns em áreas como a da saúde, por exemplo, em que o corpo é natural, segmentável, controlável e transparente. É um corpo material: "não se separa a vida biológica e a alma; não há almas individuais separadas" (ORLANDI, 2012, p. 71) do corpo, o que não é o mesmo que defini-lo como as filosofias espontâneas derivadas do biologismo, logicismo, psicologismo, sociologismo e cognitivismo (PÊCHEUX, 2009; 2011), que afastam a história e a ideologia dos processos de constituição dos sentidos.

Orlandi (2012, p. 44) ainda diz que, para compreender o que Pêcheux fala sobre tipos de análise, é preciso levar a sério a materialidade discursiva enquanto condições verbais de existência dos objetos (PÊCHEUX, 2011). Isso implica afirmar que "a materialidade específica da ideologia é o discurso e a materialidade específica do discurso é a língua" (ORLANDI, 2012, p. 83-84). Em outras palavras, a língua é o real específico (2011) das condições de significação das diferentes materialidades simbólicas. "É o interdiscurso como funcionamento da discursividade" (ORLANDI, 2012, p. 44).

Orlandi (2012, p. 45) esclarece que não se trata de reduzir as unidades de análise ao linguístico, mas de admitir que "sem o real específico da língua não temos a constituição da ideologia". Ou seja, a investigação das diferentes materialidades na análise de discurso pêcheutiana deve compreender as formas de assujeitamento, colocando como questão fundamental as "condições verbais de existência dos objetos (científicos, estéticos, ideológicos...) em uma conjuntura dada” (PÊCHEUX, 2011, p. 152). 
Assim, ao pensar o corpo enquanto efeito de sentido entre locutores, não se pode deixar de considerá-lo enquanto produto de uma determinada configuração histórica que o determina e, ainda, em relação à constituição de subjetividades. Levar em conta essas relações materiais é considerar o político, como atesta Orlandi (2005, p. 34): “enquanto relações de força que se simbolizam, ou em outras palavras, o político reside no fato de que os sentidos têm direções determinadas pela forma da organização social que se impõe a um indivíduo ideologicamente interpelado".

\title{
3 A METÁFORA COMO TRANSFERÊNCIA
}

De acordo com Orlandi (2003), ao trabalhar a forma material o analista de discurso instaura a paráfrase e a metáfora no interior de sua prática, considerando o equívoco, ou seja, a falha da língua inscrevendo-se na história. A paráfrase e a metáfora são, pois, suportes analíticos de base. Orlandi diz que ambas são definidas diferentemente pela análise de discurso. Assim, se a definição de paráfrase comum ao campo da Linguística se diferencia daquela que adotamos neste estudo, a de metáfora não é a mesma que geralmente aparece nos Estudos Literários.

Pensada em relação à configuração das formações discursivas, é a paráfrase que está na base da noção de deriva, que por sua vez se relaciona ao que Pêcheux (2009) define como efeito metafórico: fenômeno semântico fabricado por uma substituição contextual, produzindo um deslizamento de sentido. $O$ gesto de interpretação do analista, ao descrever e interpretar um discurso, opera com a paráfrase e a metáfora como constitutivas do funcionamento da discursividade:

\begin{abstract}
A paráfrase e a metáfora explicitam-se, pois, enquanto procedimentos de análise. Esta é, para mim, uma marca da especificidade da análise de discurso: ela introduz uma noção não linguística de paráfrase e uma noção de metáfora que não deriva da retórica, ou dos estudos literários, assim como uma noção de "memória" que tem suas determinações que não são psicológicas, cronológicas etc. A relação entre essas noções e o modo de procedimento da análise de discurso, ligando o que é estabilizado e o que é sujeito a equívoco, no movimento da descrição e da interpretação vai marcar profundamente os estudos da linguagem. (ORLANDI, 2003, p. 5)
\end{abstract}

Definir a metáfora como transferência é colocar, de saída, a psicanálise como constitutiva do campo da análise de discurso, especialmente a psicanálise cuja marca é a leitura althusseriana da obra de Lacan. Althusser (1985) considerava a Ciência dos sonhos de Freud uma obra fundamental, pois fora nela que o psicanalista estudara os "mecanismos" ou "leis" do sonho, reduzindo suas variantes a duas, o deslocamento e a condensação. Lacan, ao teorizar o "campo da cadeia significante", reconhece nelas as figuras essenciais da Linguística: a metonímia e a metáfora. Segundo Althusser (1985, p. 63), o lapso, o ato falho, a piada e o sintoma tornam-se "significantes, inscritos na cadeia de um discurso inconsciente, dublando, em silêncio, ou seja, em voz ensurdecedora, no desconhecimento do recalcamento, a cadeia do discurso verbal do sujeito humano". 
A metáfora é situada, desta forma, em relação ao discurso do inconsciente, introduzindo o paradoxo de um discurso duplo e uno, inconsciente e verbal, que só pode dar-se no campo da cadeia significante, no qual Lacan localiza a condensação como uma metáfora e o deslocamento como uma metonímia. A condensação se produz num nível de substituição, constituindo a metáfora, que para efetuar essa substituição sempre recalca algo: "é na relação de substituição que reside o recurso criador, a força criadora, a força de engendramento, caberia dizer, da metáfora" (LACAN, 1999, p.35).

Enquanto a metáfora diz para o sujeito o sentido recalcado, é na metonímia que ele marca o desejo, que é sempre desejo daquilo que falta: "não existe objeto a não ser metonímico, sendo o objeto do desejo objeto do desejo do Outro, e sendo o desejo sempre um desejo de Outra coisa - muito precisamente, daquilo que falta, $a$, o objeto perdido primordialmente, na medida em que Freud mostra-o sempre por ser reencontrado" (LACAN, 1999, p. 16). É desta forma que Lacan introduz a questão do desejo em relação ao grande Outro e à falta, tecendo sua teoria do objeto-a, o objeto causa do desejo. O objeto-a vem substituir o objeto de desejo para sempre perdido, que na cadeia significante aparece como objeto metonímico: "esse objeto que nunca está ali, que está sempre situado em outro lugar, que é sempre outra coisa" (p. 22). Ainda, o grande Outro, em termos lacanianos, aparece como aquele que sanciona a criação própria à linguagem, no caso, daquilo que aparecerá como metáfora e metonímia, ambas sempre em relação, determinando-se e imbricando-se no jogo da linguagem.

Assim, se Althusser coloca, apoiando-se em Lacan, a metáfora como aquilo que abala a rede de significantes, Pêcheux, por sua vez, ampara-se em suas ideias para falar de transferência de sentidos em relação com as formações discursivas, que não obstante possuem fronteiras fluidas e permeáveis: para ele, a metáfora funciona no deslizamento entre formações discursivas. É o efeito metafórico como deslizamento de sentido, produzindo uma deriva, que segundo Orlandi ${ }^{2}$ deve ser pensada em relação com sua historicidade. Assim, pensar a metáfora a partir de Lacan é estabelecer que não há sentido sem metáfora, já que a metáfora está na base do funcionamento de todo dizer. $\mathrm{Ou}$, para usar termos lacanianos, "não existe sentido senão metafórico, só surgindo o sentido da substituição de um significante por outro significante na cadeia simbólica" (LACAN, 1999, p.16).

\section{CORPO E METÁFORA: EFEITO-POLIFONIA E A ILUSÃO DE TRANSPARÊNCIA}

Passemos à análise do primeiro recorte, composto por uma postagem selecionada no site de relacionamentos Facebook, especialmente da página de um festival de música eletrônica que acontece na Bahia com periodicidade anual. A postagem é composta pelo dizer do fotógrafo Murilo Ganesh e por uma fotografia, um flash que congela um momento do referido festival, uma narratividade (ORLANDI, 2004, p. 27) abrindo-se a interpretações.

\footnotetext{
2 Segundo Orlandi (2004, p. 22-23), o efeito metafórico, para Pêcheux, é o "fenômeno semântico produzido por uma substituição", e que produz, assim, um deslizamento de sentido. "Esse deslizamento, a metáfora (tomada aqui como transferência), própria da ordem simbólica é o lugar da interpretação, da ideologia, da historicidade" (grifos da autora).
} 
Figura 1 - Recorte selecionado na página do festival de música eletrônica Universo Paralello

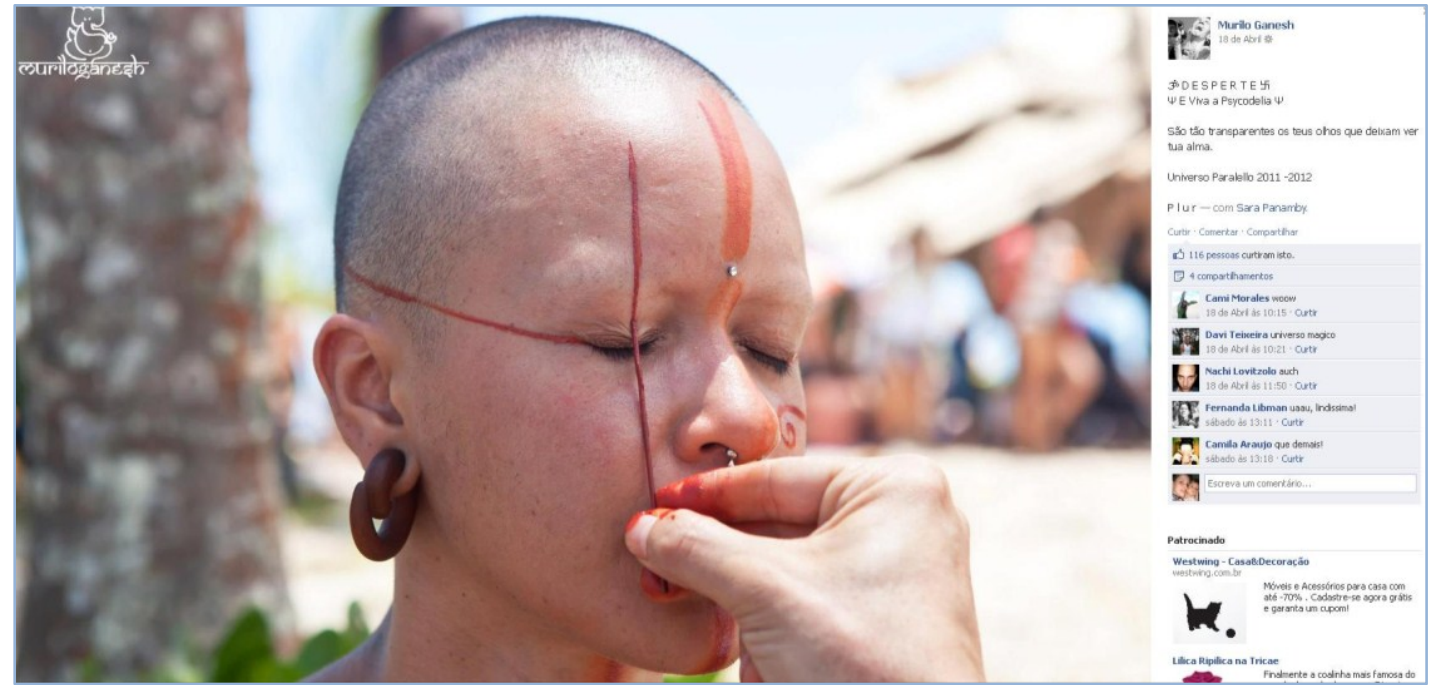

Fonte: $<$ http://www.facebook.com/universoparalelloofficial?ref=ts $\&$ fref $=$ ts $>$

Enquanto o enunciado verbal diz "Desperte e viva a psicodelia. São tão transparentes os teus olhos que deixam ver tua alma", na fotografia é possível vislumbrar uma mulher de cabelos raspados. Seu rosto é desenhado com traços vermelhos. De olhos fechados e aparência serena, é um sujeito que se prepara para a festa, pintada como os índios, porém inserida em um ritual contemporâneo do corpo.

Segundo Pêcheux (2011, p.157), a referência discursiva de um objeto é sempre construída em formações discursivas (técnicas, morais, políticas) que combinam seus efeitos em efeitos de interdiscurso. A produção discursiva de um objeto ideológico como o corpo, por exemplo, é politicamente sobredeterminada, ou seja, diante de uma ampla gama de sentidos possíveis para o corpo, posto que se trata de um objeto dividido, é a inscrição em uma ou outra formação discursiva que irá determinar seu sentido, que todavia jamais será completo. A formação discursiva dissimula sua dependência com respeito ao "todo complexo com dominante", submetido à lei de desigualdade-contradição-subordinação que caracteriza o complexo das formações ideológicas. Ou para dizer de outro modo, a formação discursiva dissimula o "fato de que 'algo fala' (ça parle) sempre antes, em outro lugar e independentemente, isto é, sob a dominação do complexo das formações discursivas" (2009, p.149).

Pois bem, na textualidade analisada, consideramos que as inscrições na pele são uma forma de metaforização de um ritual primitivo, em condições materiais e históricas outras. Isto é, a inscrição da Letra na carne "vale" pelo ritual. Elas são o lugar do interdiscurso mostrando que, pela memória, algo fala antes e em outro lugar, independentemente. Nos rituais sociais como o dos índios, a cultura acolhe um modo orgânico de significar, em ritos bem definidos, no gesto primitivo que marca o corpo do sujeito, e que tem relação com o sagrado. Na imagem em análise, a inscrição na pele é a metáfora desses ritos, que retornam na textualidade, por um intenso processo de transferência de sentidos. 
Nessa direção, também as argolas nas orelhas indicam, pelo funcionamento do interdiscurso, a inscrição em uma memória que ressignifica o grupo, a tribo, a comunidade $^{3}$. O nome do enunciador, Ganesh, semideus do hinduísmo, inserido no fio do discurso junto aos símbolos indígenas, à suástica e ao símbolo do ohm comum na tradição do yoga, fabricam um efeito de miscigenação cultural bastante comum na atualidade. Esses recursos produzem, na textualidade analisada, um corpo caleidoscópico, constituído a partir de múltiplos fragmentos de corpos outros. Diversos traços de tantas memórias, produzindo um efeito de multiplicidade, indicam que o corpo é um lugar marcado pela quantidade. E, também, lugar de sentidos que fogem, ecoam, deslizam, produzindo múltiplas possibilidades de identificação. Efeito-polifonia. E como a ideologia está relacionada ao excesso e não à falta, é justamente nesse efeito que ela se dá a ver, na quantidade estruturante de nossa formação social, no excesso de signos que marca o corpo do sujeito.

Aqui, também podemos vislumbrar o jogo entre o fora e o dentro, o esconder e o mostrar. Enquanto o enunciado verbal afirma a transparência dos olhos dizendo-os janela da alma, na fotografia a mulher mantém seus olhos fechados enquanto uma mão traça um risco vertical em sua pálpebra marcada pela tinta vermelha. É possível observar um piercing no nariz e um sinal brilhante entre as sobrancelhas raspadas: eles são, nessa nossa leitura, gestos de interpretação postos na carne, como um acréscimo que faz o corpo significar diferentemente. São também formas de metaforizar a falta, tentativas vãs de tapar o furo de nossa constituição subjetiva pelo signo impresso no corpo.

Interessante como esse recorte dá a ver o movimento do sentido, a partir da alusão à famosa frase de Leonardo da Vinci: "Não vês que o olho abraça a beleza do mundo inteiro? É janela do corpo humano, por onde a alma especula e frui a beleza do mundo" (NOVAES, 1997, p. 31). Temos, assim, um gesto que atribui poder mágico ao olhar, que espia, espreita, espiona o mundo, refletindo em si mesmo sua beleza. Olhar é, ao mesmo tempo, sair de si e trazer o mundo para dentro de si. Consequentemente, olhos são janelas e também espelhos, abertura envidraçada que atribui ao olhar um lugar importante na nossa relação com o outro, na nossa constituição subjetiva. Mas, também, dá margem para pensar a relação entre ver e saber em nossa sociedade contemporânea, na qual constantemente se diz a necessidade de "ver para crer", como se a imagem observada fosse esse estranho espelho transparente ao olhar, evidente por si só.

Mas o que a imagem, em sua relação com o enunciado verbal, dá a ver? Nas redes de memória a que se filia, no efeito-polifonia que produz, vemos formações discursivas em transferência de sentidos entre culturas diferentes, que, nessa transferência, deslocam também a função-autor ${ }^{4}$ e a forma de funcionamento da textualidade. Nessa forma de autoria contemporânea, há o desejo de tudo dizer-se, ou de dizer-se por inteiro.

\footnotetext{
${ }^{3}$ É fundamental dizer que, segundo Orlandi (2006), o momento histórico atual produz uma forma de pertencimento em que pesa uma "hipertrofia da noção de comunidade", dada a multiplicidade de discursos sobre os grupos que se proliferam em um ritmo desestabilizador. Certamente as condições históricas atuais propiciam tal proliferação, cujo efeito é visível também em nosso corpus.

${ }^{4}$ De acordo com Orlandi (2005), é pela função-autor que um texto se constitui em unidade, permitindo sua coerência e consistência. Ela é, assim, um princípio de unidade do texto que coloca, imaginariamente, o sujeito na origem do sentido e como responsável pela sua produção. A unidade e coerência do texto, sua linearidade e progressão, com início, meio e fim, sua forma integrada por diversas linguagens estão dadas pela função-autor, cujo funcionamento organiza a sequência sintática e a orientação argumentativa das
} 
Entretanto, tendo em vista o complexo com dominante das formações discursivas que determinam aquilo que pode e deve ser dito sobre o corpo do sujeito, há, na postagem em análise, sinais que, pela quantidade, explodem o sentido em ecos que deslizam, fogem, desorganizam saberes quando instituem outro lugar para a beleza fora dos estereótipos que funcionam no imaginário urbano. Desorganizam o senso comum, pelo sentido de beleza que produzem. Isso confirma o que diz Pêcheux (2009, p. 269), quando afirma que todo ritual ideológico é passível de falha. É pela desidentificação com certo sentido universalizado da beleza, pelo sentido que se movimenta, escapa, que produz outros lugares de identificação para os sujeitos.

Orlandi (2004) diz que, na prática de migração de gestos ritualísticos da identidade, há dois aspectos, do ponto de vista discursivo. O primeiro diz respeito à "tentativa (vã) de enquadrar o corpo em seus limites", pelo qual o gesto de metaforização do primitivo fica reduzido à moda, ao adorno e à sua pretensa função comunicativa. O segundo tem relação com a denúncia de um mal-estar simbólico em seu confronto com o político. Penso que, ao desorganizar o sentido da beleza, é esse confronto que a imagem produz: um outro lugar para significar a beleza, na diferença. É a marca do político, produzindo cicatriz. É o político se textualizando no corpo do sujeito.

\section{O FUNCIONAMENTO DO INTERDISCURSO: TATUAGEM E PERTENCIMENTO}

Em Semântica e discurso, Pêcheux (2009) apresenta o que pode ser considerado uma sistematização de seus procedimentos da análise discursiva, dando visibilidade ao funcionamento da ideologia e do inconsciente nos processos discursivos e na constituição do sujeito. A partir da teorização do interdiscurso como exterioridade constitutiva do discurso, o filósofo explicita o duplo funcionamento do interdiscurso: os efeitos de pré-construído e sustentação. Segundo o autor, o interdiscurso é irrepresentável, ou seja, não é acessível ao sujeito. Ele é aquilo que fala antes, em outro lugar e independentemente. É a exterioridade do discurso, cujo funcionamento se dá na filiação a uma memória discursiva, memória que não é psicológica, mas que se estrutura pelo esquecimento ${ }^{5}$ e funciona justamente pelo efeito de pré-construído ${ }^{6}$ e sustentação.

frases. Na textualidade em questão, a função-autor organiza, inclusive, a relação entre as imagens e outras materialidades simbólicas que a integram.

5 Pêcheux (2009) teoriza o duplo esquecimento em Semântica e Discurso designando-o como fundamental para a compreensão do que ele chama "transparência do sentido" e "transparência do sujeito", ambos efeitos da ideologia e do inconsciente.

${ }^{6}$ Pêcheux (2009, p. 93) define pré-construído como efeito ligado ao encaixe discursivo, para designar aquilo que aparece como preexistente ao pensamento, e que necessariamente preexiste ao sujeito, ou seja, o pré-construído fornece seu objeto ao pensamento sob a forma da exterioridade e da preexistência. Já o efeito de sustentação tem relação com a articulação entre proposições, uma evocação lateral de caráter incidente sobre a qual se apoia a tomada de posição do sujeito. Enquanto o pré-construído é um tipo de funcionamento que se define como "condição de formação do enunciado" e que fornece as coisas a saber, o discurso transverso ou efeito de sustentação é a articulação entre enunciados, que permite o engendramento da discursividade. 
Ou, para dizer de outro modo, Pêcheux explicita "a existência e os efeitos, na ideologia, do sistema acoplado de dois mecanismos: encaixe e articulação" (2009, p.122), que devem necessariamente levar em conta uma teoria não subjetivista da subjetividade, na qual os processos de imposição/dissimulação constituem o sujeito, significando para ele o que ele é e, ao mesmo tempo, dissimulando seu assujeitamento pela ilusão de sua autonomia. É sob o terreno de uma teoria não subjetivista da subjetividade que Pêcheux tece as bases de uma teoria materialista dos processos discursivos, levando necessariamente em conta a tese de Althusser, na qual figuram o recalque inconsciente e o assujeitamento ideológico, tese fundamental segundo a qual a "ideologia interpela os indivíduos em sujeitos".

\section{Figura 2 - Postagem selecionada na página do festival Universo Paralello no Facebook}

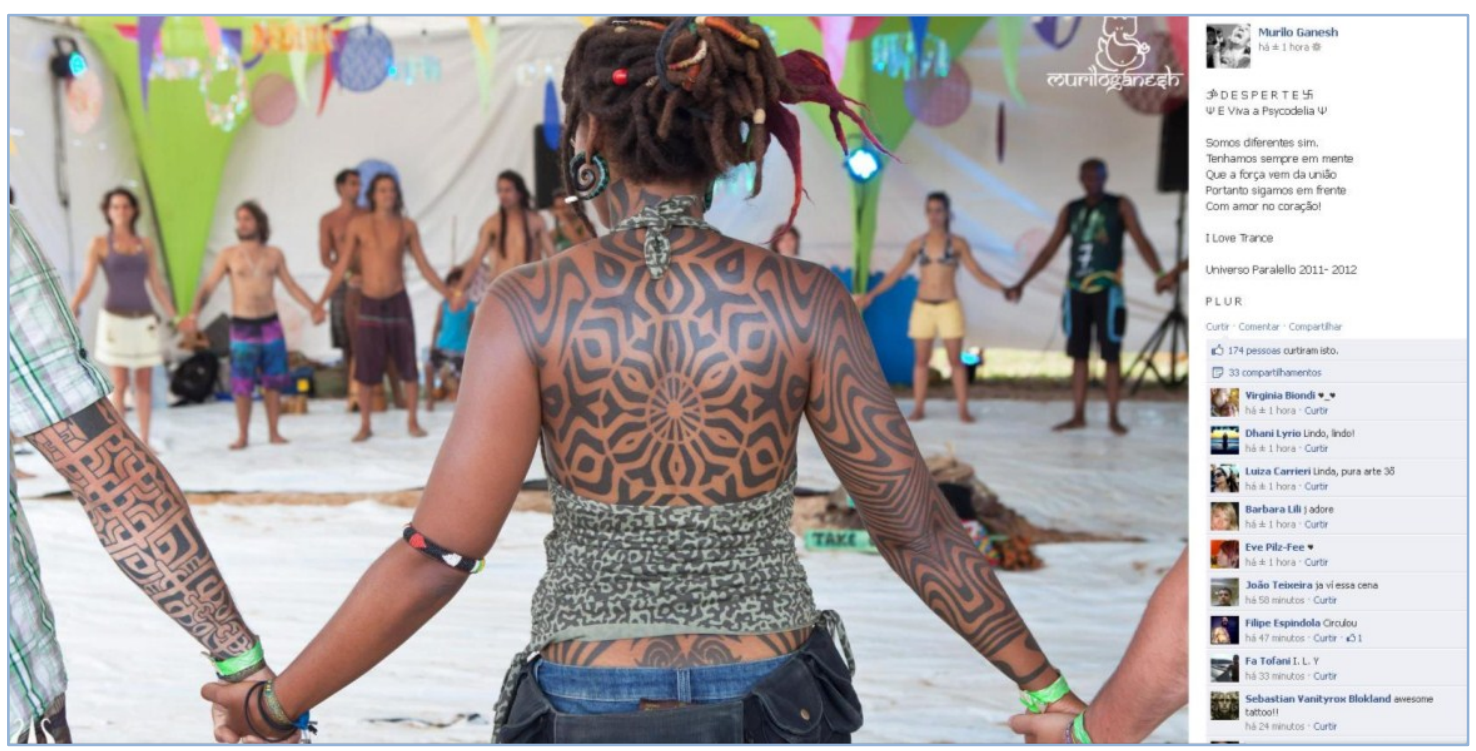

Fonte: $<$ http://www.facebook.com/universoparalelloofficial?ref $=$ ts $\&$ fref $=$ ts

Este post circula na página do festival de música eletrônica Universo Paralello, no site de relacionamentos Facebook. Nele, a fotografia apresenta a tatuagem como traço corporal distintivo que dá coesão e sustenta os sentidos do grupo: é ela que ocupa o centro da imagem e, portanto, o foco de atenção do leitor. Outros traços corporais se evidenciam: o cabelo torcido, os brincos e os adornos nos braços das pessoas que, de mãos dadas, formam um círculo. É possível afirmar que esses corpos estão em comunhão, celebram a união e a coerência do grupo. As mãos dadas simbolizam a conjunção dos corpos em um grupo-corpo (ENRIQUEZ, 2005) harmonioso e supostamente sem brechas: lugar no qual, enfim, seria possível tamponar a falta e alcançar a completude impossível.

Nesse sentido, a marcação no corpo é também marca de pertencimento a um grupo, uma vez que sinaliza a sociabilidade, marca o laço social. No grupo, o sujeito encontra um lugar para ser e pertencer, significar-se para além da morte. $O$ pertencimento, segundo Bataille (apud ENRIQUEZ, 2005, p. 31), advém do desejo dos homens em estabelecer o laço social, a aspiração à proteção, a pretensão por sentir-se parte do grupo: podemos dizer que a tatuagem, assim significada, é vinculada a sentidos específicos no interior do grupo. 
David Le Breton (2008) também indica que as tatuagens e as modificações corporais podem ser consideradas práticas de pertencimento. Segundo o autor, em diversas sociedades humanas, as tatuagens e as inscrições na carne são associadas a ritos de passagem, ou possuem significados específicos vinculados à identidade do grupo. "Em certas sociedades, a leitura da tatuagem informa a inscrição do homem em uma linhagem, um clã, uma faixa etária; indica um status e fortalece a aliança" (LE BRETON, 2008, p. 38). Segundo o autor, é impossível se misturar ao grupo sem esse trabalho de integração que os signos cutâneos imprimem na carne.

Para Orlandi (2007), o corpo do sujeito está atado ao corpo social: a corporalidade, desta maneira, é produzida na relação do sujeito com o outro, ou seja, nela o interdiscurso como exterioridade constitutiva produz seus efeitos, pela ideologia, constituindo um corpo dividido, pois é ao mesmo tempo individual e social. Isso quer dizer que a inscrição corporal produz lugares de identificação com o grupo e, ao mesmo tempo, individua esses sujeitos, pois produz neles traços singulares que marcam seus corpos. Cada tatuagem guarda em si sua diferença: elas não são iguais, visto estarem relacionadas a momentos e experiências particulares desses sujeitos.

Em outras palavras, a tatuagem é a marca da contradição de um corpo que é, ao mesmo tempo, singular e grupal: preso a processos de individuação (ORLANDI, 2012), o sujeito se tatua e modifica seu corpo num gesto que sinaliza sua necessidade de significar sua própria singularidade e, paradoxalmente, assinala sua pele identificandose com os sentidos do grupo.

Configura-se a metáfora do grupo-corpo (ENRIQUEZ, 2005), cuja coesão não pode ser pensada apenas como um conjunto de símbolos comuns (como pensam o psicologismo e o sociologismo ${ }^{7}$ ), mas como a produção de certo imaginário social comum ao grupo. Pensando os processos de individualização para o sujeito que se tatua, Orlandi (2006, p. 21) recorre à noção de esprit de corps (GUGLIELMI et al., 2005), e diz que as tatuagens favorecem a ilusão grupal, que, segundo Haroche (2005), são efeitos de sentido produzidos pelo imaginário do grupo. Comum nas formas contemporâneas de comunitarismo, essas inscrições corporais produzem pertencimento e sentido: são símbolos marcados na pele, sinais que atam o sujeito ao grupo, constituindo, neste meu gesto de leitura, um tipo de sutura. A ilusão grupal viria a preencher um déficit de laço social em uma sociedade da indiferença, da concentração e do excesso (ORLANDI, 2006). Ela sutura, por assim dizer, o laço social que une o sujeito ao outro.

Segundo Eugène Enriquez (2005), a metáfora do grupo-corpo é uma especificidade das comunidades que reflete "a crença na existência de um corpo social sólido, sem brechas", que possa vir a completar a falha constitutiva do sujeito, sua falta, e que torna possível a vida política, social e psíquica. É o que o autor afirma ao citar Bataille: "Nós não podemos nos contentar com as comunidades de fato às quais pertencemos (família, Igreja, empresa, nação etc.). Nós somos atraídos por comunidades segundas, aquelas que temos vontade de eleger" (BATAILLE apud ENRIQUEZ, 2005, p.31), nas quais cada um desempenha seu desejo de reconhecimento (seu desejo de pertencimento a um grupo idealizado), legitimando sua existência.

\footnotetext{
${ }^{7}$ O leitor de Pêcheux não terá dificuldades em reconhecer nestas denominações um conjunto de críticas formuladas pelo autor em inúmeros textos. (Cf. PÊCHEUX, 2011, p. 283-294).
} 
E acrescenta: nelas os indivíduos são regidos por um mesmo imaginário social e têm a impressão de fazer parte do grupo, acalmando a angústia da impessoalidade e da distância que marcam as sociedades democráticas individualistas. Segundo Enriquez, essas comunidades podem ser mais ou menos subversivas e possuem a particularidade de seduzir e fascinar: "capazes de despertar emoções e aptas a provocar nossa identificação" (ENRIQUEZ, 2005, p. 31). As pessoas partilham os sentidos do grupo: corpo compacto que procede através de ritos e liturgias no intuito de denegação da morte, fortalecendo o sentimento de existência e de pertencimento. "Cada grupo se distingue igualmente por seus símbolos: uma bandeira, um hino, uma maneira de falar, de se comportar, os sinais originais, os rituais prescritos [...], os jogos de palavras que forjam ou reforçam a identidade do grupo" (2005, p. 33). Símbolos que são mais eficazes quando se revestem de uma característica marginal e exótica.

\section{SENTIDOS DA DIFERENÇA: EFEITO DE PRÉ-CONSTRUÍDO E EFEITO DE SUSTENTAÇÃO}

$\mathrm{Na}$ análise, procuramos mostrar a tatuagem como um gesto que significa social e politicamente, visto ser a marca da contradição: seu traço marca um dentro e um fora do grupo, sinaliza o pertencimento, através da identificação com uma posição-sujeito específica dentro de uma dada formação discursiva.

Retomando o recorte, essa contradição também pode ser observada nos dizeres que acompanham a fotografia:

Somos diferentes sim.

Tenhamos sempre em mente

Que a força vem da união

Portanto sigamos em frente

Com amor no coração!

Figura 3 - Dizeres que acompanham a fotografia exposta na figura 2

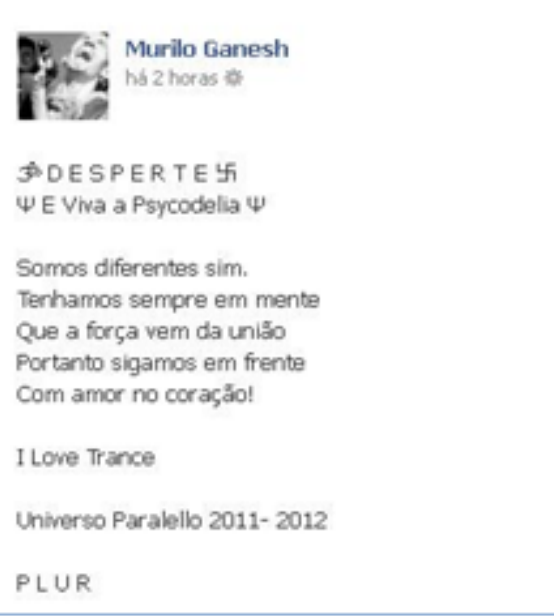

Fonte: já citada 
Neste recorte, a conjugação do verbo ser em primeira pessoa do plural "somos" funciona como enunciador coletivo identificado com o conjunto do grupo apresentado na fotografia. Isso quer dizer que o enunciador, o fotógrafo Murilo Ganesh, coloca-se numa posição-sujeito coincidente com os sentidos do grupo. Se pensarmos o "mito continuísta empírico-subjetivista" delineado por Pêcheux $(2009$, p. 117) para explicitar a posição idealista presente no funcionamento do par "articulação de enunciado/encaixe", o "nós" elidido instaura a universalização, ou seja, leva diretamente ao sujeito universal: todos somos diferentes. Entretanto, essa tomada de posição do sujeito constituindo o grupo-corpo dissimula as diferenças individuais no interior do grupo, escamoteando a contradição.

Ainda, podemos dizer que o sentido do adjetivo "diferentes" só pode ser vislumbrado se considerarmos a fotografia, o jogo entre o verbal e o não verbal: trata-se, portanto, de uma diferença que está marcada na pele do sujeito, em seu corpo.

O caráter determinativo e predicativo do adjetivo "diferentes" atribui determinadas propriedades aos sujeitos, entretanto poderíamos nos questionar: Afinal, em que consiste o sentido de "diferentes"? A teoria do discurso de Pêcheux nos permite dizer que o sentido do adjetivo "diferentes" é dado em uma exterioridade/anterioridade e, portanto, deriva de regiões específicas do interdiscurso. Há um discurso que permite determinar em que consiste esse "diferentes", seu sentido, que tem relação com o discurso de respeito à diferença tão comum em nossa formação social, discursividade que produz a evidência da diferença, sua naturalização, apagando o processo histórico que a produz e, portanto, suas contradições.

O enunciado "que a força vem da união" nos faz pensar no que Eni Orlandi (2012, p. 213) chama de onipotência no domínio social, posição fortemente presente em enunciados como "juntos podemos tudo", que segundo a autora se sustenta na quantidade e na pretensa consciência coletiva. É fácil observar que a forma-sujeito de direito se faz presente nesse enunciado: o sujeito livre e responsável investe seus sentidos no grupo, produzindo a utopia de um suposto movimento social constituído pelo "estar junto". Posto isso, podemos compreender que, face à configuração jurídica do cidadão, o discurso de elogio à igualdade ${ }^{8}$ funciona como pré-construído em relação ao primeiro enunciado, ou seja, é porque somos todos iguais perante a lei que podemos ser diferentes.

Em outras palavras, o enunciado "somos diferentes" se apoia em um saber originado em um outro lugar (de regiões do interdiscurso) e que aparece no fio do discurso como algo já-dado e, portanto, não questionável. A forma-sujeito histórica capitalista, que funciona no jurídico e em seu conjunto de direitos e deveres, apresentase como universal e sustenta os outros enunciados: para que possamos interpretá-los é necessário que o discurso de elogio à igualdade esteja, pois, em funcionamento, produzindo o efeito de pré-construído. A afirmação da diferença é sobredeterminada pelo jurídico, produzindo a forma-sujeito capitalista. O discurso de respeito à diferença aparece afirmado como um "retorno do saber no pensamento que produz uma evocação sobre a qual se apoia a tomada de posição do sujeito", e promove a articulação entre os enunciados, ou seja, "incide, na verdade, sobre a passagem à discursividade, ao

\footnotetext{
${ }^{8}$ Consideramos que a discursividade que se sustenta na pretensa igualdade entre os homens é um discurso fundador, como define Orlandi (1993), cujo marco histórico remonta à revolução francesa e à constituição da forma-sujeito de direito.
} 
engendramento do texto" (PÊCHEUX, 2009, p. 113). É um discurso transverso, tal qual define Pêcheux.

Em um texto recente, Eni Orlandi (2012, p. 24) diz que "a contradição estruturante do discurso da mundialização é a que existe entre o Um e a diferença, entre o universal e o concreto. Entre o real e o imaginário". Ou seja, com o fim da guerra fria e o nascimento de um ideal imaginário de "comunidade internacional", o mundo passa a ser significado por uma unidade ilusória que esconde as disparidades, cujo funcionamento é visível nos discursos do respeito à diferença, do assistencialismo, da crença nas tecnologias, no discurso do consumismo, etc. $\mathrm{Na}$ discursividade que analisamos isso também acontece. A universalidade irrompe como sentido primeiro e evidente, encobrindo a divisão que está na base da formação social capitalista.

\section{CONSIDERAÇÕES FINAIS}

Em ambos os recortes analisados, observa-se a multiplicidade sêmica em transferência de sentidos. Neles, os sistemas de signos não significam separadamente, verbo e imagem significam juntos, em sua relação. No modo de sua formulação, no campo de significação e interpretação que esta formulação demarca, a multiplicidade de linguagens indica o funcionamento da metáfora promovendo a intertextualidade entre elas. Por isso, considero que há múltiplos sistemas de signos em relação, produzindo transferência entre eles.

Assim, enquanto o efeito de pré-construído tem relação com uma exterioridadeanterioridade, ou seja, com a construção do objeto sob a forma da anterioridade e da preexistência, o efeito de sustentação pode ser compreendido como uma relação de implicação, lugar da reduplicação da identificação e da produção da universalização. O pré-construído, dessa forma, consiste numa "discrepância pela qual um elemento irrompe no enunciado como se tivesse sido pensado antes, em outro lugar, independentemente" (PÊCHEUX, 2009, p. 142).

No primeiro recorte, a inscrição corporal é tomada como um ritual primitivo, em uma interpretação que é metafórica, já que a inscrição "vale" pelo ritual. Nele, a marcação na pele produz um corpo que tem relação com o sagrado, ressignificado a partir de condições de produção contemporânea. No segundo recorte, as tatuagens exibem um funcionamento metonímico, uma vez que suas partes "valem" pelo todo do grupo-corpo.

Em sua relação, essas textualidades produzem um saber sobre o corpo no qual a inscrição corporal produz sentidos de multiplicidade, efeito-polifonia. Fabrica, assim, um corpo místico, no deslizamento do gesto primitivo sagrado da Letra na pele, no gesto de pertencimento que a marca no corpo engendra. Há um deslizamento de um modo específico de significar esses rituais, diz Orlandi (2004), para outras práticas situadas em nossa sociedade urbana, em condições materiais e históricas bem diferentes, nas quais há, sobretudo, um modo em que a quantidade diz do sentido. É a metáfora funcionando na base da discursividade, na relação móvel e permanente entre as formações discursivas. 
ALTHUSSER, L. Freud e Lacan. Marx e Freud: introdução crítica-histórica. 2. ed. Rio de Janeiro: Graal, 1985.

ENRIQUEZ, E.. Le ravissement du corps: Croyance et mécanismes de défense dans les communautés. In: HAROCHE, C.; GUGLIELMI, G. J. Esprit de corps, démocratie et espace public. Paris: Puf, 2005. HAROCHE, C.; GUGLIELMI, G. J. Esprit de corps, démocratie et espace public. Paris: Puf, 2005. LACAN, J. O seminário, livro 11: as formações do inconsciente. Tradução de Vera Ribeiro e Marcus André Vieira. Rio de Janeiro: Zahar, 1999.

LAGAZZI, S. Linha de Passe: a materialidade significante em análise. Rua, Campinas, v. 2, n. 16, p. 0112, fev. 2010. Disponível em: <http://www.labeurb.unicamp.br/rua/pages/pdf/16-2/10-16-2.pdf $>$. Acesso em: 27 ago. 2012.

LAKOFF, G.; JOHNSON, M. Metáforas da vida cotidiana. Campinas: Mercado de Letras, 2002.

LE BRETON, D. Adeus ao corpo: antropologia e sociedade. 3. ed. Campinas: Papirus, 2008.

NOVAES, A. O olhar. São Paulo: Companhia das Letras, 1997.

NUNES, S. R. Efeitos metafóricos no discurso de divulgação científica. In: MAGALHÃES, J. S. de; TRAVAGLIA, C. (Orgs.). Múltiplas perspectivas em Linguística. Uberlândia: EDUFU, 2008. p. 28082819.

ORLANDI, E. P. Efeitos do verbal sobre o não verbal. Rua, Campinas, n. 1, p. 35-47, 1995.

(Org.). Cidade atravessada: Os sentidos públicos no espaço urbano. Campinas: Pontes, 2001.

A Análise de discurso em suas diferentes tradições intelectuais: o Brasil. In: SEMINÁRIO DE

ESTUDOS EM ANÁLISE DE DISCURSO, 1., 2003, Porto Alegre. Anais do... Porto Alegre (RS): UFRGS, 2003. [CD-ROM].

Cidade dos sentidos. Campinas: Pontes, 2004.

Discurso e texto: formulação e circulação de sentidos. 2. ed. Campinas: Pontes, 2005.

À flor da pele: indivíduo e sociedade. In: MARIANI, B. A escrita e os escritos: reflexões em análise de discurso e psicanálise. São Carlos: Claraluz, 2006.

Interpretação: Autoria, leitura e efeitos do trabalho simbólico. 5. ed. Campinas: Pontes, 2007.

. Discurso em análise: Sujeito, sentido, ideologia. Campinas: Pontes, 2012.

PÊCHEUX, M. La frontière absente (un bilan). In: CONEIN, B. Matérialités discursives. Lille: Presses Universitaires de Lille, 1981. p. 197-207. 7-24, jul.1990.

Delimitações, inversões, deslocamentos. Caderno de Estudos Linguísticos, Campinas, n. 19, p.

. Papel da memória. In: ACHARD, Pierre et al. Papel da memória. 2. ed. Campinas: Pontes, 2007. p. 49-57.

Semântica e discurso: uma crítica à afirmação do óbvio. 4. ed. Campinas: Pontes, 2009.

. Análise automática do discurso (AAD-69). In: GADET, F.; HAK, T. Por uma análise automática do discurso: uma introdução à obra de Michel Pêcheux. 4. ed. Campinas: Editora da Unicamp, 2010. Cap. 3, p. 59-158.

Pontes, 2011.

Análise de Discurso: Michel Pêcheux. Textos escolhidos por Eni Puccinelli Orlandi. Campinas:

Recebido em: 23/09/13. Aprovado em: 03/05/14.

Title: Senses of the body: metaphor and interdiscourse

Author: Aline Fernandes de Azevedo

Abstract: Based on the theory of the body as a material form, this article introduces an analisys of two extracts from Facebook in which the main mark is the inscription on the skin of the subject, by the trace on the flesh. Here I make considerations about the functioning of the metaphor and of interdiscourse, privileging them as a way to give visibility to the theoretical and analytical procedures, while reflecting on the specifics of 
Pêcheux's discourse analysis in studies of verbal-visual textualities. The textualities examined allow one to see the inscriptions of the body as a brand of contradiction and division, signs of belonging capable of producing effects of transparency and multiplicity of meaning, in a kaleidoscopic and polyphonic body.

Keywords: Discurse Analysis. Verb-visual textualities. Body. Inscription on the skin.

Título: Sentidos del cuerpo: metáfora e inter-discurso

Autor: Aline Fernandes de Azevedo

Resumen: Sostenido en la teorización del cuerpo como forma material, este artículo presenta el análisis de dos recortes seleccionados en Facebook, y que traen como marca principal la inscripción en la piel del sujeto, por el trazo en la carne. En ello, procuro tejer consideraciones acerca del funcionamiento de la metáfora y del inter-discurso, privilegiándolos como forma de dar visibilidad a los procedimientos teóricos y analíticos, y reflejar sobre las especificidades del análisis del discurso de filiación con Pêcheux en estudios de textualidades verbo-visuales. Las textualidades analizadas permiten ver las inscripciones corporales como marca de contradicción y de división, señales de pertenecer, capaces de producir efectos de sentido de multiplicidad y transparencia en un cuerpo caleidoscópico y polifónico.

Palabras-clave: Análisis del discurso. Textualidad verbo-visual. Cuerpo. Inscripcion en la piel. 